\title{
Persediaan bahan baku dan nilai tambah usahatani jamur merang di Paguyuban Kaola Mandiri Kabupaten Jember
}

\author{
Angga Muhammad Aprianto Eka Pratama*, Soetriono \\ Joni Murti Mulyo Aji
}

Jurusan Agribisnis, Fakultas Pertanian, Universitas Jember, Indonesia

\begin{abstract}
Abstrak Penelitian ini bertujuan untuk mengetahui persediaan bahan baku usahatani jamur merang, tingkat pemesanan kembali bahan baku usahatani jamur merang dan nilai tambah usahatani jamur merang di Paguyuban Kaola Mandiri Kabupaten Jember. Lokasi penelitian ini ditentukan dengan purposive method, yaitu di Desa Rambipuji Kecamatan Rambipuji Kabupaten Jember. Metode penelitian yang digunakan yaitu metode deskriptif dan analitis. Metode pengambilan sampel yaitu menggunakan purposive sampling dengan sampel 16 orang. 15 orang di budidaya dan 1 orang sebagai pelaku pengolahan blanching. Teknik pengumpulan data yaitu primer dengan menggunakan kuisioner dan wawancara, sekunder yaitu BPS, Dinas Pertanian Kabupaten Jember, buku dan jurnal. Sedangkan analisis data yaitu Economic Order Quantity (EOQ), Reorder Point (ROP), dan nilai tambah hayami. Hasil penelitian menunjukkan persediaan bahan baku adalah ekonomis, hal ini ditunjukkan oleh kebutuhan bahan baku yang lebih kecil dari nilai EOQ. Tingkat pemesanan kembali jerami tidak ekonomis, sedangkan benih ekonomis, hal ini ditunjukkan oleh hasil ROP jerami lebih besar dari EOQ Jerami sedangkan benih Hasil ROP lebih kecil dari EOQ benih. Nilai tambah yang diperoleh menunjukkan nilai positif.
\end{abstract}

Kata kunci: persediaan; nilai tambah; usahatani; jamur merang; economic order quantity; reorder point; Jember

\begin{abstract}
This study aims to determine the raw material inventory of merang mushroom farming, the rate of re-ordering of raw material for mushroom farming and the added value of mushroom farming in Paguyuban Kaola mandiri Jember Regency. The location of this study was determined by purposive method, namely in Rambipuji Village, Rambipuji District, Jember Regency. The research method used is descriptive and analytical method. The sampling method is using purposive sampling with a sample of 16 people. 15 people involved in cultivation and another person in blanching processing. Data collection techniques are primary using questionnaires and interviews, secondary, namely BPS, Jember District Agricultural Service, books and journals. While data analysis is the Economic Order Quantity (EOQ), Reorder Point (ROP), and added value of Hayami. The results of the study show that raw material inventories are economical, this is indicated by the need for raw materials that are smaller than the EOQ value. The rate of re-ordering of straw is not economical, while the seeds are economical, this is indicated by the results of straw ROP greater than EOQ Straw while the seeds of ROP results are smaller than EOQ seeds. The added value obtained is positive.
\end{abstract}

Keywords: inventory; added value; farming; mushroom; economic order quantity; reorder point; Jember

JEL Classification: Do2; C44; Q12; D46; G31

* Penulis koresponden

E-mail: anggamaep28@gmail.com

(C) 2019 Angga Muhammad Aprianto Eka Pratama et al.

Artikel ini dimiliki oleh penulis yang dilisensikan dibawah Creative Commons Attribution 4.0

International License. Lisensi ini memungkinkan penggunaan, pendistribusian, dan pencetakan

kembali tanpa batas pada media apa pun, asalkan penulis dan sumber sebenarnya disebutkan. 


\section{PENDAHULUAN}

Menurut Soetriono et al. (2003), Pertanian adalah suatu jenis kegiatan produksi yang berlandaskan proses pertumbuhan dari tumbuh-tumbuhan dan hewan. Pertanian dalam arti sempit dinamakan pertanian rakyat sedangkan pertanian dalam arti luas meliputi pertanian dalam arti sempit, kehutanan, peternakan, dan perikanan. Semua itu merupakan hal yang sangat penting. Secara garis besar, pengertian pertanian dapat diringkas menjadi (1) proses produksi, (2) petani atau pengusaha, (3) tanah tempat usaha, (4) usaha pertanian (farm business). Salah satu produk pertanian yang memiliki prospek baik untuk dibudidayakan yaitu jamur merang.

Jamur merang (Volvariella volvaceae L) merupakan salah satu kamoditas pertanian yang mempunyai masa depan cerah utuk dikembangkan. Hingga kini sudah semakin banyak orang yang mengetahui nilai gizi jamur merang dan manfaatnya bagi kesehatan manusia. Dilain pihak produksi jamur merang di Indonesia masih sangat terbatas sehingga nilai ekonomi jamur merang semakin meningkat (Sinaga, 2011). Jamur merang dapat tumbuh pada media limbah, karena jamur mampu mendegradasi limbah organik. Kemampuannya tersebut jamur dapat dimanfaatkan untuk menambah nilai guna limbah. Jamur merang termasuk dalam golongan jamur saprofit yaitu jamur yang tumbuh pada substrat organik dari hewan maupun tumbuhan yang sudah mati dan akan mengubah substrat menjadi zat yang mudah diserap (Sunandar, 2010).

Kabupaten Jember merupakan salah satu daerah yang berada di Provinsi Jawa Timur. Kabupaten Jember merupakan salah satu daerah yang sesuai digunakan untuk budidaya tanaman hortikultura. Salah satu tanaman hortikultura yang sesuai untuk dibudidayakan yaitu jamur merang. jamur Jamur merang merupakan salah satu tanaman jenis sayuran yang memiliki prospek yang cerah dan baik untuk dikembangkan, selain memiliki kandungan gizi yang baik juga memiliki harga jual yang relatif mahal.

Berdasarkan data produksi dan produktifitas jamur di Kecamatan Rambipuji tahun 2013-2016 dapat dijelaskan bahwa produksi jamur merang di Kecamatan Rambipuji pada tahun 2013 sampai dengan tahun 2016 mengalami fluktuasi. Pada tahun 2013 produksi jamur diketahui yaitu sebesar 2.603 kwintal. Terjadi kenaikan pada tahun 2014 produksi dan produktivitas. Namun, dua tahun berikutnya mengalami penurunan produksi dan produktivitasnya. Pada tahun 2016 produksi mengalami kenaikan menjadi 76.419 kwintal. Penyebab menurunnya produksi dan produktivitas jamur, pertama dikarenakan sudah mulai berkurang yang membudidayakan jamur, ke dua bahan baku jamur kurang, ke tiga kualitas benih jamur sehingga produksi jamur dan produktivitasnya menurun. Persediaan bahan baku sangatlah penting dalam budidaya jamur merang diantaranya yaitu jerami dan benih.

Ketersedian bahan baku menjadi penting untuk diperhatikan terkait dengan kegiatan produksi dan umur simpan bahan baku yang sangat relatif singkat. Karakteristik bahan baku pada agroindustri yang umumnya mudah rusak mengakibatkan perlunya dilakukan pengendalian bahan baku. Pengendalian persediaan bahan baku ini meliputi perencanaan kebutuhan pembelian bahan baku serta pengaturan waktu yang tepat saat melakukan pembelian bahan baku (Rangkuti dalam Dermawan \& Muhaimin, 2015).

Berdasarkan hal tersebut maka peneliti ingin bertujuan untuk mengetahui: 1) persediaan bahan baku usahatani jamur merang di Paguyuban Kaola Mandiri Kabupaten Jember, 2) tingkat pemesanan kembali bahan baku usahatani jamur 
merang di Paguyuban Kaola Mandiri Kabupaten Jember dan 3) nilai tambah usahatani jamur merang di Paguyuban Kaola Mandiri Kabupaten Jember.

\section{KAJIAN PUSTAKA}

Bahan baku menjadi kebutuhan utama yang harus dipenuhi oleh sebuah perusahan, agroindustri, maupun kelompok tani. Menurut Rangkuti (dalam Dermawan \& Muhaimin, 2015) menyatakan bahwa ketersediaan bahan baku menjadi penting untuk diperhatikan terkait dengan kegiatan produksi dan umur simpan bahan baku yang sangat relatif singkat. Karakteristik bahan baku pada agroindustri yang umumnya mudah rusak mengakibatkan perlunya dilakukan pengendalian bahan baku. Salah satu yang digunakan yaitu menggunakan metode Economic Order Quantity (EOQ).

Menurut Kasmir dan Jakfar (2003), EOQ merupakan jumlah pembelian bahan mentah pada setiap kali pesan dengan biaya yang paling rendah. Artinya setiap kali memesan bahan mentah perusahaan dapat menghemat biaya yang akan dikeluarkan. Hal-hal yang berkaitan dengan EOQ dan sangat perlu diperhatikan adalah masalah klasifikasi biaya. Pentingnya kasifikasi biaya akan memudahkan kita dalam melakukan analisis, sehingga hasil yang akan diperoleh dapat diakui kebenarannya. Menurut Fahmi (2012), model EOQ merupakan model matematik yang menentukan jumlah barang yang harus dipesan untuk memenuhi permintaan diproyeksikan, dengan biaya persediaan yang diminimalkan.

Secara umum ada tiga bentuk variabel dalam Economic Order Quantity yang terlihat jelas yaitu:

a. Total cost atau biaya total. Merupakan keseluruhan biaya yang dikeluarkan dalam suatu masa yang terjadi.

b. Ordering cost atau biaya pesanan. Merupakan keseluruhan biaya yang dikeluarkan selama dalam proses pembelian.

c. Carrying cost atau biaya penyimpanan. Merupakan biaya-biaya yang dikeluarkan sehubungan dengan penyimpanan.

Menurut Kasmir dan Jakfar (2003), ROP merupakan waktu perusahaan akan memesan kembali atau batas waktu pemesanan kembali dengan melihat jumlah minimal persediaan yang ada. Hal ini penting agar supaya jangan sampai terjadi kekurangan bahan pada saat dibutuhkan. Jumlah pemesanan kembali dihitung dengan probabilitas atau kemungkinan terjadinya kekurangan stock dan dihitung selama tenggang waktu.

Komoditi pertanian pada umumnya dihasilkan sebagai bahan mentah dan mudah rusak, sehingga perlu langsung dikonsumsi atau langsung diolah terlebih dahulu. Proses pengolahan ini dapat meningkatkan guna bentuk komoditi-komoditi pertanian. Kesediaan konsumen membayar harga output agroindustri pada harga yang relatif tinggi merupakan insentif bagi perusahaan-perusahaan pengolah untuk menghasilkan output agroindustri Sudiyono (2002). Menurut Sudiyono (2002), Besarnya nilai tambah karena proses pengolahan didapat dan pengurangan biaya bahan baku dan input lainnya terhadap nilai prosuk yang dihasilkan, tidak termasuk tenaga kerja. Dengan kata lain nilai tambah menggambarkan imbalan bagi tenaga kerja, modal dan manajemen. 


\section{METODE PENELITIAN}

Penentuan daerah penelitian ini dilakukan secara sengaja (purposive method). Dasar pertimbangan pemilihan lokasi penelitian ini yaitu pada Paguyuban Kaola Mandiri, karena daerah tersebut merupakan salah satu daerah yang melakukan budidaya jamur merang. Selain itu Paguyuban Kaola Mandiri juga melakukan proses pengolahan blanching pada produk jamur merang.

Metode penelitian yang digunakan dalam penelitian ini adalah metode penelitian deskriptif analitis. Metode yang digunakan dalam pengambilan contoh adalah Purposive Sampling. Menurut Sugiyono (2014), metode Purposive Sampling adalah teknik penentuan sampel dengan pertimbangan tertentu. Responden yang dipilih untuk dijadikan contoh dalam penelitian ini harus memiliki syarat-syarat tertentu, syarat tersebut diantaranya adalah memiliki pemahaman dan kemampuan terhadap permasalahan persediaan bahan baku jamur merang, melakukan proses pengolahan blanching jamur merang. Responden yang akan diambil adalah Paguyuban Kaola mandiri Kabupaten Jember beserta anggotanya, dimana 1 orang sebagai pelaku di Pengolahan blanching dan 15 orang sebagai anggota yang melakukan budidaya jamur merang, dimana hasil usahataninya digunakan sebagai bahan baku blanching.

Teknik pengumpulan data yaitu menggunakan data primer dan data sekunder. Data primer yang digunakan yaitu menggunakan kuisioner (angket) dan wawancara (interview). Sedangkan data sekunder yang digunakan yaitu buku, jurnal.

Metode analisis data yang digunakan yaitu pertama tentang persediaan bahan baku jamur merang menggunakan analisis EOQ dengan formulasi sebagai berikut (Fahmi, 2012):

$$
\mathrm{EOQ}=\sqrt{\frac{2(\mathrm{D})(\mathrm{OC})}{\mathrm{CC}}}
$$

Keterangan:

$$
\begin{aligned}
& \text { EOQ = economic order quantity } \\
& D \quad=\text { permintaan tahunan (demand) } \\
& \text { OC = biaya pemesanan (ordering cost) } \\
& \text { CC = biaya penyimpanan (carrying cost) }
\end{aligned}
$$

Kriteria pengambilan keputusan EOQ:

1. Jika jumlah kebutuhan bahan baku lebih kecil $(<)$ dari jumlah $E O Q$ maka pemesanan bahan baku dikatakan ekonomis.

2. Jika jumlah kebutuhan bahan baku lebih besar (>) dari jumlah EOQ maka pemesanan bahan baku dikatakan tidak ekonomis.

Metode analisis data kedua yang digunakan yaitu tingkat pemesanan kembali menggunakan analisis Reorder Point (ROP) dengan formulasi sebagai berikut (Herjanto, 1999):

$$
R O P=d x L+S S
$$

Keterangan:

ROP $=$ Titik pemesanan kembali (Reorder Point)

$\mathrm{d} \quad=$ Tingkat kebutuhan per unit waktu

SS = Persediaan pengaman (Safety Stock)

$\mathrm{L} \quad$ = waktu tenggang (Lead Time)

Kriteria pengambilan keputusan ROP: 
1. Jika jumlah tingkat pemesanan kembali (ROP) kurang dari $(<)$ jumlah kebutuhan bahan baku ekonomis (EOQ) maka tidak akan terjadi kekurangan bahan baku dan dikatakan efisien.

2. Jika jumlah tingkat pemesanan kembali (ROP) atau lebih dari (>) jumlah kebutuhan bahan baku ekonomis (EOQ) maka akan terjadi kekurangan bahan baku dan dikatakan tidak efisien.

Metode analisis data ketiga yang digunakan yaitu tentang nilai tambah jamur merang menggunakan analisis nilai tambah metode Hayami (dalam Marimin \& Maghfiroh, 2010) dengan formulasi sebagai berikut:

Tabel 1. Analisis Nilai Tambah Metode Hayami

\begin{tabular}{cll}
\hline No & \multicolumn{1}{c}{ Variabel } & Nilai \\
\hline \multicolumn{2}{c}{ Output, Input, dan Harga } & $(1)$ \\
\hline 1. & Output $(\mathrm{Kg})$ & $(2)$ \\
2. & Bahan baku $(\mathrm{Kg})$ & $(3)$ \\
3. & Tenaga kerja langsung (HOK) & $(4)=(1) /(2)$ \\
4. & Faktor konversi & $(5)=(3) /(2)$ \\
5. & Koefisien tenaga kerja langsung (HOK/Kg) & $(6)$ \\
6. & Harga Output (Rp/Kg) & $(7)$ \\
$7 . \quad$ Upah tenaga kerja langsung (Rp/HOK) & \\
\hline
\end{tabular}

Penerimaan dan Keuntungan
8. Harga bahan baku $(\mathrm{Rp} / \mathrm{Kg})$
(8)
9. Harga input lain $(\mathrm{Rp} / \mathrm{Kg})$
10. Nilai output $(\mathrm{Rp} / \mathrm{Kg})$
11. a. Nilai tambah $(\mathrm{Rp} / \mathrm{Kg})$
b. Rasio nilai tambah (\%)
12. a. Pendapatatan tenaga kerja langsung $(\mathrm{Rp} / \mathrm{Kg})$
b. Pangsa tenaga kerja langsung (\%)
13. a. Keuntungan $(\mathrm{Rp} / \mathrm{Kg})$
b. Tingkat Keuntungan (\%)
(9)
$(10)=(4) \times(6)$
$(11 a)=(10)-(8)-(9)$
$(11 \mathrm{~b})=(11 \mathrm{a}) /(10) \times 100$
$(12 a)=(5) \times(7)$
$(12 \mathrm{~b})=(12 \mathrm{a}) /(11 \mathrm{a}) \times 100$
$(13 a)=(11 a)-(12 a)$
$(13 b)=(13 a) /(10) \times 100$

Sumber: Marimin dan Maghfiroh, 2010

Kriteria pengambilan keputusan nilai tambah yaitu sebagai berikut:

a. Jika nilai tambah $(>$ ) dari 0 , maka proses pengolahan jamur merang dengan cara perebusan (blanching) memberikan nilai tambah.

b. Jika nilai tambah ( $\leq$ ) 0 , maka proses pengolahan jamur merang dengan cara perebusan (blanching) tidak memberikan nilai tambah.

\section{HASIL DAN PEMBAHASAN}

\section{Tingkat EOQ Usahatani Jamur Merang di Paguyuban Kaola Mandiri Kabupaten Jember}

Pemesanan bahan baku ekonomis di Paguyuban Kaola Mandiri Kabupaten Jember dapat diketahui dengan menggunakan perhitungan EOQ. Berikut ini adalah perhitungan pemesanan bahan baku ekonomis EOQ pada Paguyuban Kaola Mandiri Kabupaten Jember dapat dilihat pada Tabel 2. Berdasarkan Tabel 2 Kebutuhan bahan baku dalam satu kali proses produksi di Paguyuban Kaola Mandiri Kabupaten Jember untuk jerami yaitu $55.133 \mathrm{~kg}$, sedangkan benih yaitu $190 \mathrm{~kg}$. Rata-rata kebutuhan bahan baku jerami per kumbung yaitu 599,27 kg, sedangkan benih per 
kumbung yaitu 2,06 kg. Tabel 2 menunjukkan perhitungan EOQ di Paguyuban Kaola Mandiri Kabupaten Jember dalam satu kali proses produksi. Pemesanan ekonomis bahan baku jerami dalam satu kali proses produksi yaitu sebesar 97.144,79 kg sedangkan pemesanan ekonomis bahan baku jerami per kumbung yaitu sebesar $1.055,92 \mathrm{~kg}$. Pemesanan ekonomis bahan baku benih dalam satu kali proses produksi yaitu sebesar $211,07 \mathrm{~kg}$, sedangkan pemesanan ekonomis bahan baku benih per kumbung yaitu sebesar 2,29.

Tabel 2. Pemesanan Bahan Baku Ekonomis (EOQ) di Paguyuban Kaola Mandiri Kabupaten Jember

\begin{tabular}{|c|c|c|c|c|c|c|c|}
\hline \multirow[t]{2}{*}{$\begin{array}{c}\text { No } \\
\text { Responden }\end{array}$} & \multirow[t]{2}{*}{$\begin{array}{c}\text { Rata-rata } \\
\text { Jumlah } \\
\text { Kumbung } \\
\text { berproduksi }\end{array}$} & \multicolumn{2}{|c|}{$\begin{array}{c}\text { Rata-Rata Biaya } \\
\text { Pemesanan/Produksi } \\
\text { (Rp) }\end{array}$} & \multicolumn{2}{|c|}{$\begin{array}{c}\text { Rata-Rata } \\
\text { Kebutuhan Bahan } \\
\text { Baku/Produksi } \\
\text { (Kg) }\end{array}$} & \multicolumn{2}{|c|}{$\begin{array}{l}\text { Pemesanan } \\
\text { ekonomis } \\
\text { (EOQ) } \\
(\mathrm{Kg})\end{array}$} \\
\hline & & Jerami & Benih & Jerami & Benih & Jerami & Benih \\
\hline 1 & 3 & 150.500 & 10.500 & 1.800 & 6 & $3.291,8$ & 9,16 \\
\hline 2 & 18 & 712.111 & 11.000 & $10.666,6$ & 36 & $21.455,80$ & 22,97 \\
\hline 3 & 6 & 240.500 & 20.500 & 3.600 & 12 & $5.884,89$ & 18,11 \\
\hline 4 & 6 & 225.000 & 21.000 & 3.360 & 11 & $5.499,09$ & 17,54 \\
\hline 5 & 2 & 60.500 & 5.500 & 1.200 & 4 & $1.704,11$ & 5,41 \\
\hline 6 & 2 & 60.500 & 5.500 & 1.200 & 4 & $1.704,11$ & 5,41 \\
\hline 7 & 5 & 162.500 & 5.500 & 3.240 & 11 & $4.589,11$ & 8,98 \\
\hline 8 & 6 & 321.000 & 11.000 & 3.840 & 13 & $7.021,79$ & 13,8 \\
\hline 9 & 6 & 224.500 & 15.500 & 3.360 & 11 & $5.492,97$ & 15,07 \\
\hline 10 & 4 & 241.000 & 16.000 & 2.400 & 8 & $4.809,98$ & 13,06 \\
\hline 11 & 8 & 406.055 & 15.500 & $4.866,6$ & 16 & $8.890,68$ & 18,18 \\
\hline 12 & 7 & 356.055 & 15.500 & $4.266,6$ & 14 & $7.795,24$ & 17 \\
\hline 13 & 11 & 436.555 & 11.000 & $6.533,3$ & 28 & $10.681,09$ & 20,26 \\
\hline 14 & 4 & 161.000 & 16.000 & 2.400 & 8 & $3.931,41$ & 13,06 \\
\hline 15 & 4 & 201.000 & 16.000 & 2.400 & 8 & $4.392,72$ & 13,06 \\
\hline Jumlah & 92 & 3.958 .776 & 196.000 & $55.133,1$ & 190 & 97.144.79 & 211,07 \\
\hline \multicolumn{2}{|c|}{ Rata-rata Per Kumbung } & 43.030 & 13.066 & 599,27 & 2,06 & $1.055,92$ & 2,29 \\
\hline
\end{tabular}

Sumber: Data primer diolah, 2018

Berdasarkan perhitungan yang telah dilakukan dapat dikatakan bahwa EOQ pada jerami dikatakan ekonomis karena nilai kebutuhan bahan baku rata-rata dalam satu kumbung sebesar 599,27 kg lebih kecil daripada nilai EOQ jerami sebesar $1.055,92 \mathrm{~kg}$. Selanjutnya pada bahan baku benih dapat dikatakan ekonomis karena nilai kebutuhan rata-rata sebesar 2,06 kg lebih kecil daripada nilai EOQ benih sebesar $2,29 \mathrm{~kg}$. Nilai EOQ bahan baku jerami dan benih pada Paguyuban Kaola Mandiri Kabupaten Jember diperoleh dari hasil berdasarkan perhitungan akar 2 dikali dengan jumlah biaya pemesanan bahan baku jerami dan benih per produksi (40 hari) dikali dengan kebutuhan bahan baku jerami dan benih per produksi dan dibagi dengan jumlah biaya penyimpanan bahan baku jerami dan benih per produksi.

\section{Tingkat ROP Bahan Baku Usahatani Jamur Merang di Paguyuban Kaola Mandiri Kabupaten Jember}

Tingkat pemesanan kembali ROP di Paguyuban Kaola Mandiri Kabupaten Jember. Tingkat pemesanan kembali bahan baku jamur merang dianalisis dengan menggunakan analisis ROP dapat dilihat pada Tabel 3 dan Tabel 4.

Tabel 3 menunjukkan bahan baku jerami yang digunakan dalam usahatani jamur merang di Paguyuban Kaola Mandiri Kabupaten Jember. Kebutuhan jerami dalam satu kali proses produksi dengan jumlah kumbung yang berproduksi yaitu 92 kumbung adalah sebesar $55.133,1 \mathrm{~kg}$, sedangkan kebutuhan rata-rata dalam satu kumbung yaitu 599,27 kg. berdasarkan perhitungan ROP diketahui bahwa tingkat 
pemesanan kembali bahan baku jerami dalam satu kali proses produksi yaitu 860.290 $\mathrm{kg}$ dengan pemesanan kembali per kumbung yaitu 9.350,97 kg.

Tabel 3. Tingkat Pemesanan Kembali (ROP) Bahan Baku Jerami Usahatani Jamur Merang di Paguyuban Kaola Mandiri

\begin{tabular}{ccccccr}
\hline $\begin{array}{c}\text { No } \\
\text { Responden }\end{array}$ & $\begin{array}{c}\text { Jumlah } \\
\text { Kumbung }\end{array}$ & $\begin{array}{c}\text { Rata-Rata } \\
\text { Jumlah } \\
\text { Kumbung } \\
\text { Berproduksi }\end{array}$ & $\begin{array}{c}\text { Jumlah Kebutuhan } \\
\text { BB Jerami/Produksi } \\
(\mathbf{K g})\end{array}$ & $\begin{array}{c}\text { Lead } \\
\text { Time } \\
\text { (Hari) }\end{array}$ & $\begin{array}{c}\text { Safety } \\
\text { Stock }\end{array}$ & $\begin{array}{c}\text { ROP } \\
(\text { Kg) }\end{array}$ \\
\hline 1 & 3 & 3 & 1.800 & 14 & 0 & 25.200 \\
2 & 20 & 18 & $10.666,6$ & 16 & 0 & 170.666 \\
3 & 6 & 6 & 3.600 & 15 & 0 & 54.000 \\
4 & 6 & 6 & 3.360 & 16 & 0 & 53.760 \\
5 & 2 & 2 & 1.200 & 17 & 0 & 20.400 \\
6 & 2 & 2 & 1.200 & 16 & 0 & 19.200 \\
7 & 6 & 5 & 3.240 & 16 & 0 & 51.840 \\
8 & 7 & 6 & 3.840 & 14 & 0 & 53.760 \\
9 & 6 & 6 & 3.360 & 15 & 0 & 50.400 \\
10 & 4 & 4 & 2.400 & 16 & 0 & 38.400 \\
11 & 9 & 8 & $4.866,6$ & 16 & 0 & $77.865,6$ \\
12 & 8 & 7 & $4.266,6$ & 16 & 0 & $68.265,6$ \\
13 & 12 & 11 & $6.533,3$ & 16 & 0 & 104.533 \\
14 & 4 & 4 & 2.400 & 16 & 0 & 38.400 \\
15 & 4 & 4 & 2.400 & 14 & 0 & 33.600 \\
\hline Jumlah & 99 & $\mathbf{9 2}$ & $\mathbf{5 5 . 1 3 3 . 1}$ & $\mathbf{2 3 3}$ & & $\mathbf{8 6 0 . 2 9 0}$ \\
\hline Rata-rata & & & $\mathbf{5 9 9 . 2 7}$ & $\mathbf{1 6}$ & & $\mathbf{9 . 3 5 0 , 9 7}$ \\
\hline
\end{tabular}

Sumber: Data Primer diolah, 2018

Berdasarkan Tabel 2 diperoleh EOQ jerami sebesar 1.055,92 kg menunjukkan bahwa jumlah yang dipesan sebesar $1.055,92 \mathrm{~kg}$ dengan nilai pemesanan kembali ROP sebesar $9.350,97 \mathrm{~kg}$. Persediaan akan tiba 16 hari setelah pemesanan. Jumlah bahan baku akan kembali maksimal pada tingkat 9.350,97 kg. Tingkat pemesanan kembali bahan baku jerami di Paguyuban Kaola Mandiri adalah tidak efisien karena tingkat pemesanan kembali sebesar $9.350,97 \mathrm{~kg}$ lebih besar dari tingkat kebutuhan bahan baku EOQ jerami sebesar $1.055,92 \mathrm{~kg}$, dengan demikian Paguyuban Kaola Mandiri akan mengalami kekurangan bahan baku jerami.

Tabel 4. Tingkat Pemesanan Kembali (ROP) Bahan Baku Benih Usahatani Jamur Merang di Paguyuban Kaola Mandiri

\begin{tabular}{|c|c|c|c|c|c|c|}
\hline $\begin{array}{c}\text { No } \\
\text { Responden }\end{array}$ & $\begin{array}{l}\text { Jumlah } \\
\text { Kumbung }\end{array}$ & $\begin{array}{l}\text { Rata-Rata Jumlah } \\
\text { Kumbung } \\
\text { Berproduksi }\end{array}$ & $\begin{array}{c}\text { Jumlah } \\
\text { Kebutuhan BB } \\
\text { Benih/Produksi } \\
(\mathrm{Kg}) \\
\end{array}$ & $\begin{array}{l}\text { Lead } \\
\text { Time } \\
\text { (Hari) }\end{array}$ & $\begin{array}{l}\text { Safety } \\
\text { Stock }\end{array}$ & $\begin{array}{l}\text { ROP } \\
(\mathrm{Kg})\end{array}$ \\
\hline 1 & 3 & 3 & 6 & 1 & 0 & 6 \\
\hline 2 & 20 & 18 & 36 & 1 & 0 & 36 \\
\hline 3 & 6 & 6 & 12 & 1 & 0 & 12 \\
\hline 4 & 6 & 6 & 11 & 1 & 0 & 11 \\
\hline 5 & 2 & 2 & 4 & 1 & 0 & 4 \\
\hline 6 & 2 & 2 & 4 & 1 & 0 & 4 \\
\hline 7 & 6 & 5 & 11 & 1 & 0 & 11 \\
\hline 8 & 7 & 6 & 13 & 1 & 0 & 13 \\
\hline 9 & 6 & 6 & 11 & 1 & 0 & 11 \\
\hline 10 & 4 & 4 & 8 & 1 & 0 & 8 \\
\hline 11 & 9 & 8 & 16 & 1 & 0 & 16 \\
\hline 12 & 8 & 7 & 14 & 1 & 0 & 14 \\
\hline 13 & 12 & 11 & 28 & 1 & 0 & 28 \\
\hline 14 & 4 & 4 & 8 & 1 & 0 & 8 \\
\hline 15 & 4 & 4 & 8 & 1 & 0 & 8 \\
\hline Jumlah & 99 & 92 & 190 & 15 & & 190 \\
\hline Rata-rata & & & 2.06522 & 1 & & 2.06522 \\
\hline
\end{tabular}

Sumber: Data Primer diolah, 2018 
Berdasarkan Tabel 4 dapat diketahui bahwa bahan baku benih yang digunakan dalam usahatani jamur merang di Paguyuban Kaola Mandiri Kabupaten Jember. Kebutuhan benih dalam satu kali proses produksi dengan jumlah kumbung yang berproduksi yaitu 92 kumbung adalah sebesar $190 \mathrm{~kg}$, sedangkan kebutuhan benih rata-rata dalam satu kumbung yaitu 2,06 kg. berdasarkan perhitungan ROP diketahui bahwa tingkat pemesanan kembali bahan baku benih dalam satu kali proses produksi yaitu $190 \mathrm{~kg}$ dengan pemesanan kembali per kumbung yaitu 2,06 kg.

\section{Nilai Tambah Olahan Jamur Merang pada Paguyuban Kaola Mandiri Kabupaten Jember}

Tabel 5. Perhitungan Nilai Tambah Pengolahan Jamur Merang Blanching Ratarata Bulan Juli dan Agustus 2018 Paguyuban Kaola Mandiri Kabupaten Jember

\begin{tabular}{|c|c|c|c|}
\hline No & Variabel (Satuan) & Keterangan & Nilai \\
\hline \multicolumn{4}{|c|}{ Output, Input, dan Harga } \\
\hline \multirow{5}{*}{$\begin{array}{l}1 \\
2 \\
3 \\
4 \\
5\end{array}$} & \multirow{7}{*}{$\begin{array}{l}\text { Output }(\mathrm{Kg}) \\
\text { Bahan baku }(\mathrm{Kg}) \\
\text { Tenaga kerja langsung (HOK) } \\
\text { Faktor konversi } \\
\text { Koefisien tenaga kerja langsung } \\
\text { (HOK/Kg) } \\
\text { Harga Output (Rp/Kg) } \\
\text { Upah tenaga kerja langsung } \\
\text { (Rp/HOK) }\end{array}$} & -1 & 132 \\
\hline & & -2 & 188 \\
\hline & & -3 & 1 \\
\hline & & $(4)=(1) /(2)$ & 0,7021 \\
\hline & & $(5)=(3) /(2)$ & 0.0053 \\
\hline \multirow{2}{*}{$\begin{array}{l}6 \\
7\end{array}$} & & -6 & 45.000 \\
\hline & & -7 & 132.000 \\
\hline \multicolumn{4}{|c|}{ Penerimaan dan Keuntungan } \\
\hline & Harga bahan baku $(\mathrm{Rp} / \mathrm{Kg})$ & -8 & 16.000 \\
\hline & Harga input lain $(\mathrm{Rp} / \mathrm{Kg})$ & -9 & \\
\hline & $\begin{array}{l}\text { Biaya penyusutan alat } \\
\text { produksi }(\mathrm{Rp} / \mathrm{Kg})\end{array}$ & & 15,08 \\
\hline 10 & Nilai output $(\mathrm{Rp} / \mathrm{Kg})$ & $(10)=(4) \times(6)$ & $31.595,74$ \\
\hline 11 & $\begin{array}{l}\text { a. Nilai tambah }(\mathrm{Rp} / \mathrm{Kg}) \\
\text { b. Rasio nilai tambah }(\%)\end{array}$ & $\begin{array}{l}(11 \mathrm{a})=(10)-(8)-(9) \\
(11 \mathrm{~b})=(11 \mathrm{a}) /(10) \times 100\end{array}$ & $\begin{array}{r}15.580,66 \\
49,3125\end{array}$ \\
\hline \multirow[t]{2}{*}{12} & $\begin{array}{l}\text { a. Pendapatatan tenaga kerja } \\
\text { langsung }(\mathrm{Rp} / \mathrm{Kg})\end{array}$ & $(12 \mathrm{a})=(5) \times(7)$ & 702,1276 \\
\hline & $\begin{array}{l}\text { b. Pangsa tenaga kerja langsung } \\
(\%)\end{array}$ & $(12 b)=(12 a) /(11 a) \times 100$ & 4,5064 \\
\hline 13 & $\begin{array}{l}\text { a. Keuntungan }(\mathrm{Rp} / \mathrm{Kg}) \\
\text { b. Tingkat Keuntungan (\%) }\end{array}$ & $\begin{array}{l}(13 a)=(11 a)-(12 a) \\
(13 b)=(13 a) /(11 a) \times 100\end{array}$ & $\begin{array}{r}14.878,53 \\
95,4935\end{array}$ \\
\hline
\end{tabular}

Sumber: Data primer diolah, 2018

Berdasarkan hasil analisis nilai tambah pada Tabel 5 dapat diketahui bahwa ratarata bahan baku yang digunakan untuk pengolahan jamur merang blanching pada bulan juli dan agustus 2018 di Paguyuban Kaola Mandiri Kabupaten Jember yaitu 188 $\mathrm{kg}$, dengan harga bahan baku per kilogram sebesar Rp 16.0000. Bahan baku $188 \mathrm{~kg}$ menghasilkan output sebesar $132 \mathrm{~kg}$. Faktor konversi menujukkan 0,7 artinya bahwa bahan baku 1 Kilogram jamur merang menghasilkan 0,7 kg jamur merang blanching.

Harga output jamur merang dengan proses pengolahan blanching sebesar Rp 45.000 per $\mathrm{kg}$, nilai tersebut diperoleh dari kesepakatan antara ketua Paguyuban Kaola Mandiri Kabupaten Jember dengan perusahaan yang memesan jamur merang blanching tersebut. Proses pengolahan jamur merang hanya membutuhkan 1 orang pekerja yaitu dimulai dari penimbangan, pengangkatan atau pemindahan jamur yang sudah ditimbang ke tempat pengolahan dan proses pengolahan blanching. Koefisien tenaga kerja menunjukkan bahwa rata-rata waktu yang dibutuhkan dalam 
pengolahan jamur merang per kilogram yaitu 0,0053 hari per $\mathrm{kg}$ dalam satu kali proses produksi. Upah tenaga kerja yang diperoleh dari seberapa banyak output bahan baku yang dihasilkan. Semakin banyak output bahan baku yang dihasilkan dalam satu kali proses produksi maka semakin banyak upah yang didapatkan oleh pekerja. Upah tenaga kerja Per kilogram output bahan baku jamur merang blanching yaitu Rp 1000. Output yang di hasilkan yaitu $132 \mathrm{~kg}$ jadi upah yang didapatkan tenaga kerja pengolahan jamur merang blanching Rp 132.000.

Besarnya nilai tambah jamur merang pengolahan blanching di Paguyuban Kaola Mandiri dipengaruhi oleh ketersediaan bahan baku, harga bahan baku, harga jual output pengolaha jamur merang blanching per kilogram dan harga input lain yang terkait dalam proses pengolahan jamur merang blanching. Input lain dalam proses pengolahan jamur merang yaitu kompor, dandang, serok, drum plastik, bak atau keranjang plastik, tabung LPG $3 \mathrm{~kg}$, timbangan, pajak bangunan. Input lain tersebut merupakan alat yang digunakan dalam proses produksi, biaya penyusutan alat produksi tersebut yaitu Rp 15,08 per kilogram.

Berdasarkan perhitungan nilai tambah yang dilakukan oleh Paguyuban Kaola Mandiri diperoleh hasil Rp 15.580,66 per kilogram atau bernilai positif artinya yaitu pengolahan yang dilakukan mampu memberikan nilai lebih dibandingkan dengan produk awal atau bahan baku. hal ini didukung oleh penelitian Putri (2013) bahwa nilai tambah dari pengolahan jamur menjadi crispy dan nugget memberikan nilai tambah sebesar Rp 22.545 dan Rp 54.295 per kilogram atau bernilai positif. Dapat ditarik kesimpulan bahwa dari hasil penelitian ini dan penelitian yang dilakukan Oleh (Putri, 2013) sama-sama memberikan nilai tambah yang positif.

Pendapatan tenaga kerja langsung yang diperoleh di Paguyuban Kaola Mandiri yaitu Rp 702 per kilogram, artinya setiap pengolahan jamur merang dalam $1 \mathrm{Kg}$ memperoleh pendapatan sebesar $\mathrm{Rp}$ 702. Keuntungan yang diperoleh oleh Paguyuban Kaola Mandiri dalam pengolahan jamur merang blanching yaitu sebesar Rp 14.878 per kilogram. Hal ini sejalan dengan penelitian Putri (2013) pendapatan tenaga kerja yang diperoleh dari pengolahan jamur menjadi crispy dan dan nugget yaitu sebesar Rp 9.285,63 per kilogram dan Rp 12.075 per kilogram dengan keuntungan sebesar Rp 16.259,38 per kilogram dan Rp 42.220 per kilogram. Dapat ditarik kesimpulan bahwa keuntungan pada penelitian ini dengan penelitian Putri bernilai positif artinya pengolahan perebusan (blanching) yang dilakukan oleh peneliti dengan penelitian Putri mampu memberikan nilai lebih dibandingkan dengan produk awal. Berdasarkan kriteria pengambilan keputusan menyatakan bahwa jika pengolahan blanching memiliki nilai lebih besar dari 0 maka pengolahan tersebut memberikan nilai tambah, apabila pengolahan blanching lebih kecil atau sama dengan 0 maka pengolahan tersebut tidak akan memberikan nilai tambah dan usaha tersebut tidak layak untuk dijalankan.

\section{KESIMPULAN}

Pemesanan ekonomis bahan baku jerami dan benih pada Paguyuban Kaola Mandiri dengan menggunakan EOQ adalah ekonomis hal ini ditunjukkan oleh pemesanan bahan baku jerami dan benih lebih kecil dari perhitungan EOQ. Tingkat pemesanan kembali ROP bahan baku jerami tidak efisien, hal ini disebabkan oleh nilai ROP jerami yang lebih besar dari EOQ jerami sedangkan untuk ROP benih adalah efisien, hal ini disebabkan oleh nilai ROP benih lebih kecil dari EOQ benih. Pengolahan jamur merang dengan cara blanching mampu memberikan nilai tambah 
yang positif. Nilai tambah yang diperoleh pengolahan blanching adalah sebesar Rp 15.580,66 per kilogram.

Paguyuban Kaola Mandiri harus menciptakan suatu inovasi agar media tanam tidak tergantung pada batang tanaman padi, melakukan pengeringan jerami dan memiliki tempat penyimpanan jerami yang baik seperti gudang penyimpanan, sehingga pada saat jerami sulit atau terlambat datang bisa memanfaatkan bahan baku tersebut. Selain itu juga harus membuat benih sendiri untuk meminimalkan harga dari bahan baku benih jamur merang. Mengembangkan produk olahan jamur merang selain blanching yaitu melakukan pengemasan (packing) terhadap hasil pengolahan tersebut dan pemasaran harus diperluas.

\section{DAFTAR PUSTAKA}

(1) Dermawan, J., \& Muhaimin, A.W. (2015). Perencanaan dan Pengendalian Bahan Baku Jamur Tiram di Industri Rumah Tangga Ailani Kota Malang Jawa Timur. Jurnal Habitat, 26(1), 22-30. https://doi.org/10.21776/ub.habitat.2015.026.1.3

(2) Fahmi, I. (2012). Manajemen Produksi dan Operasi. Bandung, Indonesia: Alfabeta.

(3) Herjanto, E. (1999). Manajemen Produksi dan Operasi. Bogor, Indonesia: Grasindo.

(4) Kasmir, \& Jakfar. (2003). Studi Kelayakan Bisnis. Jakarta, Indonesia: Kencana.

(5) Marimin, \& Maghfiroh, N. (2010). Aplikasi Teknik Pengambilan Keputusan Dalam Manajemen Rantai Pasok. Bogor, Indonesia: IPB Press.

(6) Sinaga, M.S. (2011). Budidaya Jamur Merang. Jakarta, Indonesia: Penebar Swadaya.

(7) Soetriono, Anik, S., \& Rijanto. (2003). Pengantar IImu Pertanian. Malang, Indonesia: Bayumedia.

(8) Sudiyono, A. (2002). Pemasaran Pertanian. Malang, Indonesia: UMM Press.

(9) Sugiyono. (2014). Metode Penelitian Kuantitatif Kualitatif dan R\&D. Bandung, Indonesia: Alfabeta.

(10) Sunandar, B. (2010). Budidaya Jamur Merang. Bandung, Indonesia: Agroinovasi. 